\title{
Strontium-induced rat egg activation
}

\author{
R Tomashov-Matar ${ }^{1}$, D Tchetchik ${ }^{1}$, A Eldar ${ }^{1}$, R Kaplan-Kraicer ${ }^{1}$, Y Oron $^{2}$ and R Shalgi ${ }^{1}$ \\ Departments of ${ }^{1}$ Cell and Developmental Biology and ${ }^{2}$ Physiology and Pharmacology, Sackler Faculty of \\ Medicine, Tel Aviv University, Ramat-Aviv 69978 Tel-Aviv, Israel
}

Correspondence should be addressed to R Shalgi; Email: shalgir@post.tau.ac.il

R Tomashov-Matar and D Tchetchik contributed equally to this work

\begin{abstract}
Parthenogenetic agents that evoke cytosolic calcium concentration $\left(\left[\mathrm{Ca}^{2+}\right]_{i}\right)$ oscillations similar to those evoked by sperm, mimic fertilization more faithfully than agents that trigger a single $\left[\mathrm{Ca}^{2+}\right]_{i}$ transient. Strontium chloride $\left(\mathrm{SrCl}_{2}\right)$ binds to and activates the $\mathrm{Ca}^{2+}$-binding site on the inositol 1,4,5-trisphosphate receptor and evokes $\left[\mathrm{Ca}^{2+}\right]_{\mathrm{i}}$ oscillations. Although $\mathrm{SrCl}_{2}$ has been reported to activate mouse eggs, little is known regarding the pattern of the $\left[\mathrm{Ca}^{2+}\right]_{i}$ oscillations it evokes in rat eggs and their effect on the early events of egg activation: cortical granule exocytosis (CGE) and completion of meiosis (CM). In the current study we investigated the effect of various concentrations of $\mathrm{SrCl}_{2}(2,4$ or $6 \mathrm{mM})$ on $\left[\mathrm{Ca}^{2+}\right]_{\mathrm{i}}$, by monitoring $\left[\mathrm{Ca}^{2+}\right]_{\mathrm{i}}$ oscillations in fura-2-loaded rat eggs. Treatment with $2 \mathrm{mM} \mathrm{SrCl}_{2}$ was optimal for inducing the first $\left[\mathrm{Ca}^{2+}\right]_{\mathrm{i}}$ transient, which was similar in duration to that triggered by sperm. However, the frequency and duration of the subsequent $\left[\mathrm{Ca}^{2+}\right]_{\mathrm{i}}$ oscillations were lower and longer in $\mathrm{SrCl}_{2}$-activated than in sperm-activated eggs. The degree of CGE was identical in eggs activated by either sperm or $\mathrm{SrCl}_{2}$, as assessed by semi-quantitative immunohistochemistry combined with confocal microscopy. Evoking 1, 2 or $10\left[\mathrm{Ca}^{2+}\right]_{i}$ oscillations $\left(8,15\right.$ or $60 \mathrm{~min}$ in $\mathrm{SrCl}_{2}$ respectively) had no effect on the intensity of fluorescent CGE reporter dyes, while 60-min exposure to $\mathrm{SrCl}_{2}$ caused a delay in $\mathrm{CM}$. Our results demonstrate that $\mathrm{SrCl}_{2}$ is an effective parthenogenetic agent that mimics rat egg activation by sperm, as judged by the generation of $\left[\mathrm{Ca}^{2+}\right]_{i}$ oscillations, CGE and CM.

Reproduction (2005) $130467-474$
\end{abstract}

\section{Introduction}

The initial increase in cytosolic calcium concentration $\left(\left[\mathrm{Ca}^{2+}\right]_{i}\right)$ occurring immediately after sperm-egg interaction at fertilization is necessary for triggering two majors events: cortical granule exocytosis (CGE) and stimulation of the cell cycle resumption to complete meiosis (CM), collectively known as egg activation (Whitaker \& Larman 2001). This concept is supported by evidence derived from experiments performed with eggs of several species, including the rat (Raz \& Shalgi 1998): (1) the actual increase in $\left[\mathrm{Ca}^{2+}\right]_{i}$ within the fertilized egg cytoplasm, (2) the initiation of egg development by parthenogenetically activating a rise in $\left[\mathrm{Ca}^{2+}\right]_{i}$, and (3) the prevention of egg development initiation by suppression of the $\left[\mathrm{Ca}^{2+}\right]_{i}$ rise (Kline \& Kline 1992). The signaling pathway responsible for initiating and mediating $\left[\mathrm{Ca}^{2+}\right]_{i}$ increase has been studied by several research groups. It has been shown that mammalian eggs express phospholipase C (Dupont et al. 1996, Mehlmann et al. 1998), which, when activated, hydrolyzes phosphatidylinositol 4,5-bisphosphate to the second messenger inositol 1,4,5- trisphosphate ( $\operatorname{lns}_{3}$ ). Ins $P_{3}$ interacts with $\operatorname{InsP}_{3}$ receptors $\left(\operatorname{InsP}_{3} R\right)$ at the endoplasmic reticulum, thus inducing $\mathrm{Ca}^{2+}$ release (Patel et al. 1999). CM is mediated by a decrease in activity of both the cytostatic factor and the M-phase promoting factor, a heterodimer comprised of catalytic, CDK1, and regulatory, cyclin B1, components (Nixon et al. 2000, Carroll 2001). Recent studies have demonstrated that $\mathrm{Ca}^{2+}$ mediates the degradation of cyclin B1 by increasing the activity of an E3 ubiquitin ligase (Hyslop et al. 2004, Jones 2004).

Sperm-egg fusion initiates $\left[\mathrm{Ca}^{2+}\right]_{\mathrm{i}}$ oscillations within the egg that last several hours (Fissore et al. 1992). A fertilization-like $\left[\mathrm{Ca}^{2+}\right]_{i}$ oscillation frequency dramatically increases the extent of parthenogenetic development of newly ovulated eggs, as compared with a single $\mathrm{Ca}^{2+}$ stimulus (Ozil \& Huneau 2001), whereas an abnormally high frequency of oscillations results in cell death (Gordo et al. 2000). Some activators, such as ionomycin or ethanol, cause a single $\left[\mathrm{Ca}^{2+}\right]_{i}$ transient, while others such as Ins $\mathrm{P}_{3}$, adenophostin $\mathrm{A}$, thimerosal and strontium $\left(\mathrm{SrCl}_{2}\right)$ evoke repetitive $\left[\mathrm{Ca}^{2+}\right]_{i}$ oscillations (Jellerette et al. 2000). $\mathrm{SrCl}_{2}$ binds to and activates the $\mathrm{Ca}^{2+}$-binding site on the InsP ${ }_{3} R$ (Kline \& Kline 1992, Marshall \& Taylor 1994); moreover, $\mathrm{SrCl}_{2}$-mediated $\left[\mathrm{Ca}^{2+}\right]_{i}$ oscillations are generated via 
the InsP $\mathrm{P}_{3} \mathrm{R}$ (Brind et al. 2000). There are three known isoforms of Ins $\mathrm{P}_{3} \mathrm{R}$ that are expressed, to different extents, in various cell types. In mouse eggs, type I InsP $\mathrm{P}_{3} \mathrm{R}$ is by far the most abundant isoform; however, mRNAs of all isoforms are present within the egg (Parrington et al. 1998). The InsP $\mathrm{P}_{3} \mathrm{Rs}$ form tetramers at the membrane of the endoplas$\mathrm{mic}$ reticulum. The tetramers consist of a large cytoplasmic domain that contains the $\operatorname{Ins}_{3}$ binding site, a membranespanning region that contains the $\mathrm{Ca}^{2+}$ channel, a small cytoplasmic C-terminus, and a large $\mathrm{N}$-terminal cytoplasmic region that provides the main region for cytoplasmic regulators to act (Brind et al. 2000). Ins $\mathrm{P}_{3} \mathrm{Rs}$ are regulated by small modulators such as $\mathrm{InsP}_{3}, \mathrm{Ca}^{2+}$ and ATP, as well as by protein-protein type interactions with large proteins like calmodulin and FKBP12 (Taylor 1998). Another mechanism for the long-term regulation of $\operatorname{InsP}_{3} \mathrm{R}$ activity is its downregulation by proteolysis, probably by the proteasome (Brind et al. 2000).

$\mathrm{SrCl}_{2}$ is a known activator of mouse eggs ( $\mathrm{O}^{\prime}$ Neill et al. 1991, Wakayama et al. 1998, Kishikawa et al. 1999, Otaegui et al. 1999), but little is known regarding its effectiveness in activating rat eggs. It has recently been reported that $\mathrm{SrCl}_{2}$ effectively activated rat eggs and triggered development to the blastocyst stage (Krivokharchenko et al. 2003). However, no information was presented regarding the dynamics of $\left[\mathrm{Ca}^{2+}\right]_{i}$ and its effect on the early events of egg activation (CGE, CM).

$\mathrm{SrCl}_{2}$ provides a simple yet tightly-controlled technique of egg activation. It is added directly to the medium, without the need for microinjection and the possible damage to the egg membrane, whereas the extent of $\left[\mathrm{Ca}^{2+}\right]_{i}$ signal and its duration are easily controlled by $\mathrm{SrCl}_{2}$ concentration and time of exposure. In the current study, we monitored $\left[\mathrm{Ca}^{2+}\right]_{\mathrm{i}}$ changes during incubation with various $\mathrm{SrCl}_{2}$ concentrations and established the optimal concentration for the occurrence of CGE and of CM. We also studied the effect of the number of $\mathrm{SrCl}_{2}$-induced $\left[\mathrm{Ca}^{2+}\right]_{i}$ transients on CGE and CM. Although $\mathrm{SrCl}_{2}$ is extensively used as a parthenogenetic activator of eggs in a number of species (Tateno \& Kamiguchi 1997, Okada et al. 2003) and its action has been described in considerable detail in the mouse egg (Kline \& Kline 1992, Bos-Mikich et al. 1993), the present report is the first comprehensive study relating $\mathrm{SrCl}_{2}$ parthenogenetic activation of rat eggs to the early events of fertilization - $\left[\mathrm{Ca}^{2+}\right]_{i}$ dynamics, CGE and CM.

\section{Materials and Methods}

\section{Animals}

Wistar-derived rats were housed in air-conditioned, lightcontrolled rooms, with food and water available ad libitum. Twenty-three- to twenty-five-day-old female rats were primed with a subcutaneous injection of 10 IU pregnant mare's serum gonadotropin (PMSG; Syncro-Part, Sanofi, Paris, France). An intraperitoneal injection of $10 \mathrm{IU}$ human chorionic gonadotropin (hCG; Sigma Chemical Co., St Louis, MO, USA) was administered 48-54 h after PMSG.

\section{Collection of eggs}

Ovulated eggs at metaphase II (MII) were isolated, $14 \mathrm{~h}$ after hCG injection, from the oviductal ampullae into regular or $\mathrm{Ca}^{2+}$ - and $\mathrm{Mg}^{2+}$-free culture medium (Toyoda HEPES (TH or $\mathrm{TH}-/-$ ) supplemented with $0.4 \%$ BSA; Talmor et al. 1998). Cumulus cells were removed by hyaluronidase $(400 \mathrm{lU} / \mathrm{ml}$, Sigma). For in vitro fertilization, eggs were treated with $\alpha$-chemotrypsin $(50 \mu \mathrm{g} / \mathrm{ml}$, Sigma) to remove the zona pellucida (ZP) prior to insemination. All manipulations were performed on a warm plate $\left(37^{\circ} \mathrm{C}\right)$.

\section{Parthenogenetic activation}

Eggs were parthenogenetically activated by either calcium ionophore (ionomycin 407950; Calbiochem, San Diego, CA, USA) or $\mathrm{SrCl}_{2}$. Aliquots of $4 \mathrm{mM}$ ionomycin in dimethylsulfoxide (DMSO) were kept at $-70^{\circ} \mathrm{C}$ and diluted to the final concentration of $2 \mu \mathrm{M}$ just before use in $\mathrm{TH}-1-$ medium. Freshly prepared $\mathrm{SrCl}_{2}(2,4$ or $6 \mathrm{mM}$ in $\mathrm{TH}-1-$ medium) was used. MII eggs were incubated for $5 \mathrm{~min}$ in the presence of ionomycin and then for $0,10,25,40,55$ or $70 \mathrm{~min}$ in fresh $\mathrm{TH}$ medium without ionomycin. Other batches of MII eggs were incubated for 8,15 or $60 \mathrm{~min}$ in the presence of various concentrations of $\mathrm{SrCl}_{2}$ followed by additional incubation in $\mathrm{SrCl}_{2}$-free TH medium, up to a total incubation period of 15, 30, 45, 60 or $75 \mathrm{~min}$. For details, see the Results section.

\section{In vivo/in vitro fertilization}

PMSG- and hCG-primed female rats were allowed to mate overnight with males of proven fertility. In vivo fertilized eggs were isolated from the oviductal ampullae of animals, $15.5 \mathrm{~h}$ after hCG administration, into TH medium, and their cumulus cells were removed as described earlier for MII eggs.

For in vitro fertilization, spermatozoa were collected from the uteri shortly after mating, and diluted in rat fertilization medium (Ben-Yosef et al. 1993) to a final concentration of 0.7 to $1.3 \times 10^{6}$ spermatozoa $/ \mathrm{ml}$. Insemination of ZP-free eggs by capacitated sperm was performed in a thermostatic chamber, suitable for $\left[\mathrm{Ca}^{2+}\right]_{i}$ measurements, as previously described (Ben-Yosef et al. 1996).

\section{Measurement of $\left[\mathrm{Ca}^{2+}\right]_{i}$}

To follow $\left[\mathrm{Ca}^{2+}\right]_{\mathrm{i}}$ changes, MII eggs, either ZP-enclosed or ZP-free, were collected as described and loaded with the $\mathrm{Ca}^{2+}$-sensitive dye, fura-2-AM (3 $\mu \mathrm{M}$; Molecular Probes, Eugene, OR, USA), for $30 \mathrm{~min}$ in $\mathrm{TH}$ medium at $37^{\circ} \mathrm{C}$. Eggs were washed free of the dye and allowed to attach to a poly-L-lysine coated coverslip, in $\mathrm{TH}-/-$ medium, under mineral oil. The coverslip was placed in a thermostatic 
chamber adjusted to $37 \pm 1{ }^{\circ} \mathrm{C}$. Free $\left[\mathrm{Ca}^{2+}\right]_{\mathrm{i}}$ was determined by monitoring the fluorescence ratio at 340/380 nm using an inverted microscope (Nikon TMD; Nikon Corp, Tokyo, Japan), attached to an imaging workstation, controlled by Metamorph and Metafluor software (Universal Imaging, Downingston, PA, USA).

\section{DNA staining and CGE quantification}

Eggs were fixed in 3\% paraformaldehyde, stained with Lens culinaris agglutinin (LCA; Vector, Burlingame, CA, USA) and costained with Texas-red streptavidin (Vector) for detection of CGE (Eliyahu \& Shalgi 2002) and labeled with Hoechst 33342 (Sigma) for determining cell cycle and fertilization status (Shalgi \& Phillips 1988). Labeled eggs were visualized and photographed with a Zeiss confocal laser-scanning microscope (LSM). The Zeiss LSM 410 (Oberkochen, Germany) is equipped with a UV laser (Coherent Inc. Santa Clara, CA, USA) and with a $25 \mathrm{~mW}$ krypton-argon laser and a $10 \mathrm{~mW}$ helium-neon laser (488, 543, and 633 maximum lines). A $40 \times$ NA/1.2 planapochromat water-immersion lens (Axiovert 135 M, Zeiss) was used for all imaging. Confocal micrographs of 3-4 eggs from each experimental group were analyzed by densitometry. The staining intensity was calculated using the corrected mean density values obtained by the LSM software (Abbott et al. 1999).

\section{Statistical analysis}

Data were evaluated by one-way ANOVA, and differences between treatment groups were determined by using a Chi-square test; $P<0.01$ was considered significant.

\section{Results}

\section{The effect of $\mathrm{SrCl}_{2}$ concentration on $\left[\mathrm{Ca}^{2+}\right]_{i}$ oscillations}

A very early observable event occurring after sperm-egg interaction or after parthenogenetic activation is an increase in $\left[\mathrm{Ca}^{2+}\right]_{i}$, which leads to the early events of egg activation (i.e. CGE and CM). We examined the amplitude and the duration of $\left[\mathrm{Ca}^{2+}\right]_{i}$ oscillations in MII triggered by 2, 4 or $6 \mathrm{mM} \mathrm{SrCl}_{2}$ and compared them to those caused by fertilization or by ionomycin (Table 1). All three concentrations of $\mathrm{SrCl}_{2}$ triggered an initial $\left[\mathrm{Ca}^{2+}\right]_{\mathrm{i}}$ transient that was followed by a series of $\left[\mathrm{Ca}^{2+}\right]_{i}$ oscillations of shorter duration and lower amplitude. The oscillations in individual eggs were repetitive with regular peak-to-peak intervals. Eggs treated with either 2 or $4 \mathrm{mM} \mathrm{SrCl}_{2}$ exhibited no significant differences in the duration or frequency of $\mathrm{Ca}^{2+}$ oscillations, which were similar to those observed during in vitro fertilization. The amplitude of the initial $\left[\mathrm{Ca}^{2+}\right]_{\mathrm{i}}$ transient induced by $\mathrm{SrCl}_{2}$ (regardless of concentration) was higher than that of the following $\left[\mathrm{Ca}^{2+}\right]_{i}$ oscillations (Fig. 1B-D), whereas the amplitude of the first sperm-induced transient was lower than the following $\left[\mathrm{Ca}^{2+}\right]_{\mathrm{i}}$ oscillations $(P<0.01$; Fig. 1A). The oscillations induced by $\mathrm{SrCl}_{2}$ were of longer duration (i.e. they had longer peak-to-peak intervals) than those induced by sperm (Fig. 1A-D). The duration and amplitude of the first $\left[\mathrm{Ca}^{2+}\right]_{\mathrm{i}}$ transient induced by $6 \mathrm{mM} \mathrm{SrCl}_{2}$ were higher and significantly longer than those induced by either 2 or $4 \mathrm{mM} \mathrm{SrCl}_{2}$ or those exhibited during fertilization $(P<0.01$; Table 1, Fig. 1B-D). As expected, repetitive oscillations continued as long as $\mathrm{SrCl}_{2}$ was present in the culture medium (data not shown).

The duration of the single transient induced by ionomycin was longer than the duration of the first transient induced by 2 or $4 \mathrm{mM} \mathrm{SrCl}_{2}$ or by sperm, but was shorter than the one induced by $6 \mathrm{mM} \mathrm{SrCl}_{2}$. Its amplitude was lower than any of the first peaks induced by either sperm or $\mathrm{SrCl}_{2}$ (Table 1).

\section{The effect on egg activation of a single $\left[\mathrm{Ca}^{2+}\right]_{i}$ transient, induced by either $\mathrm{SrCl}_{2}$ or ionomycin}

We evaluated the effect on $\mathrm{CM}$ of a single $\left[\mathrm{Ca}^{2+}\right]_{\mathrm{i}}$ transient induced by $\mathrm{SrCl}_{2}$. As presented in Table 1, the second $\left[\mathrm{Ca}^{2+}\right]_{\mathrm{i}}$ transient, in $\mathrm{SrCl}_{2}$-activated eggs, occurs $12.2 \pm 3.2 \mathrm{~min}$ post exposure to $\mathrm{SrCl}_{2}$. We thus exposed the eggs for $8 \mathrm{~min}$ to 2,4 or $6 \mathrm{mM} \mathrm{SrCl}_{2}$ in $\mathrm{TH}-1-$ medium followed by incubation in TH medium. After $30 \mathrm{~min}$ in culture (8 min in $\mathrm{SrCl}_{2}$ and 22 additional min in $\mathrm{TH}$ ), more than half of the eggs reached anaphase in a dosedependent manner $(53 \%, 78 \%$ or $88 \%$ induced by 2,4 or $6 \mathrm{mM} \mathrm{SrCl}_{2}$ respectively; $P<0.01$ ), whereas 45 min were sufficient for $31-39 \%$ of the eggs to reach telophase at all $\mathrm{SrCl}_{2}$ concentrations tested. After $60 \mathrm{~min}, 56 \%$ of the eggs induced by $4 \mathrm{mM} \mathrm{SrCl}_{2}$ extruded polar body (PBII) while

Table 1 The effect of egg activators on $\mathrm{Ca}^{2+}$ oscillations. All values are presented as means \pm S.E.M.

\begin{tabular}{|c|c|c|c|c|c|c|}
\hline \multirow[b]{2}{*}{ Conditions } & \multirow[b]{2}{*}{ Eggs $(n)$} & \multicolumn{2}{|r|}{ First peak } & \multicolumn{3}{|c|}{ Oscillations } \\
\hline & & Duration (min) & Amplitude (arbitrary units) & Duration (min) & Amplitude (arbitrary units) & Peak-to-peak interval (min) \\
\hline $2 \mathrm{mM} \mathrm{SrCl}_{2}$ & 13 & $9.71 \pm 2.61^{a}$ & $7.28 \pm 1.99$ & $3.63 \pm 1.38$ & $4.50 \pm 0.64$ & $6.71 \pm 2.05$ \\
\hline $4 \mathrm{mM} \mathrm{SrCl}_{2}$ & 22 & $9.72 \pm 3.20^{\mathrm{a}}$ & $5.90 \pm 1.80$ & $3.66 \pm 1.36$ & $4.39 \pm 1.30$ & $7.13 \pm 1.98$ \\
\hline $6 \mathrm{mM} \mathrm{SrCl}_{2}$ & 14 & $14.75 \pm 2.38^{\mathrm{a}^{*}}$ & $9.03 \pm 3.23$ & $4.13 \pm 0.90$ & $5.51 \pm 0.97$ & $6.67 \pm 2.54$ \\
\hline Fertilization & 3 & $9.00 \pm 1.00$ & $7.50 \pm 1.87$ & $2.50 \pm 0.70$ & $8.50 \pm 2.88^{*}$ & $2.02 \pm 0.40$ \\
\hline lonomycin & 9 & $11.15 \pm 1.93$ & $3.82 \pm 0.54$ & - & - & - \\
\hline
\end{tabular}

${ }^{\text {a }}$ Measured as the time interval between the exposure to $\mathrm{SrCl}_{2}$ until the $\left[\mathrm{Ca}^{2+}\right]_{\mathrm{i}}$ level returned to baseline.

$* P<0.01$ statistically different. 

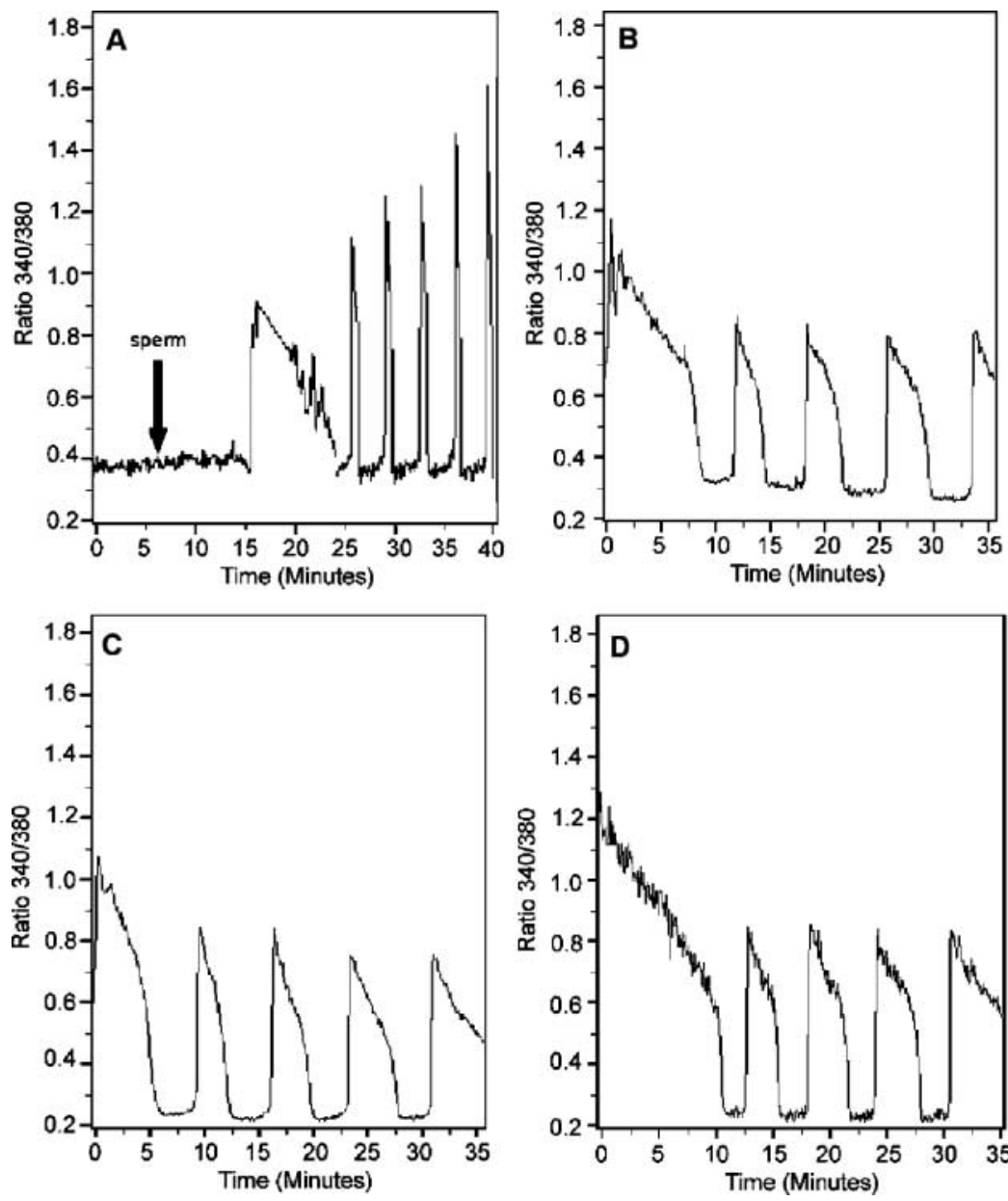

Figure 1 Fertilization and $\mathrm{SrCl}_{2}$-induced $\mathrm{Ca}^{2+}$ oscillations. $\left[\mathrm{Ca}^{2+}\right]_{\mathrm{i}}$ in fura-2AM-loaded rat eggs that were either fertilized in vitro (A) or parthenogenetically activated by $2 \mathrm{mM}(\mathrm{B}), 4 \mathrm{mM}$ (C) or $6 \mathrm{mM}$ (D) only $42 \%$ and $34 \%$ of the eggs were induced to do so by 6 or by $2 \mathrm{mM} \mathrm{SrCl}_{2}$ respectively $(P<0.01$; Fig. 2$)$. The membrane of most of the eggs that were activated by $6 \mathrm{mM}$ $\mathrm{SrCl}_{2}$ was undulated (light microscopy; data not shown). $\mathrm{CM}$ induced by $1 \mathrm{mM} \mathrm{SrCl} 2$ was very slow - only a small percentage of eggs extruded PBII after $75 \mathrm{~min}$ in culture (data not shown).

Exposure of eggs to $2 \mu \mathrm{M}$ ionomycin for $5 \mathrm{~min}$ induced a single $\left[\mathrm{Ca}^{2+}\right]_{\mathrm{i}}$ transient which triggered both CGE and CM (Raz \& Shalgi 1998). We compared the effect of ionomycin on egg activation with the effect of a single $\left[\mathrm{Ca}^{2+}\right]_{i}$ transient induced by $2 \mathrm{mM} \mathrm{SrCl} 2$. We exposed eggs for $5 \mathrm{~min}$ to $2 \mu \mathrm{M}$ ionomycin, or for $8 \mathrm{~min}$ to $2 \mathrm{mM} \mathrm{SrCl}_{2}$, in $\mathrm{TH}-1-$ medium. Eggs were then washed and cultured for additional time periods in $\mathrm{TH}$ to complete a total of $15,30,45,60$ or $75 \mathrm{~min}$ in culture. The differences in the degree of $\mathrm{CM}$ between eggs exposed to either activator were not statistically significant (Fig. 3). Thirty minutes after exposure to either $\mathrm{SrCl}_{2}$ or ionomycin, more than $50 \%$ of the eggs reached anaphase, (54\% and 58\% respectively; $P<0.01)$. Fifteen minutes later, the eggs reached telophase $(36 \%$ and $29 \%$ respectively; $P<0.01$ ) and extruded PBII in another $30 \mathrm{~min}(70 \%$ and $71 \%$ respectively; $P<0.01$; Fig. 3 ).
We also compared the effects of $\mathrm{SrCl}_{2}$ and ionomycin on CGE intensity. Eggs were incubated in $\mathrm{TH}-1-$ medium for $8 \mathrm{~min}$ in the presence of $2 \mathrm{mM} \mathrm{SrCl}_{2}$, or for $5 \mathrm{~min}$ in the presence of $2 \mu \mathrm{M}$ ionomycin. Eggs were then transferred for additional time periods to $\mathrm{TH}$ medium to complete $45 \mathrm{~min}$ in culture, then fixed and labeled for CGE and for DNA. The degree of CGE was calculated by the LSM program. The values representing CGE in $\mathrm{SrCl}_{2}-$ activated eggs were expressed relative to those obtained for ionomycin-activated eggs, which were arbitrarily set at 1.0. The single $\left[\mathrm{Ca}^{2+}\right]_{\mathrm{i}}$ transient induced by both activators caused CGE in all examined eggs. However, the intensity of the reaction differed between the two activators. The CGE intensity induced by $2 \mathrm{mM} \mathrm{SrCl}_{2}$ was almost double $(1.89 \pm 0.19)$ that induced by $2 \mu \mathrm{M}$ ionomycin, but was similar to sperm-induced CGE (1.81 \pm 0.08 ; Table 2, Fig. 4).

\section{The effect of $\left[\mathrm{Ca}^{2+}\right]_{i}$ oscillations induced by $\mathrm{SrCl}_{2}$ on egg activation}

The observation that CGE is more sensitive to $\left[\mathrm{Ca}^{2+}\right]_{\mathrm{i}}$ increase than CM (Raz et al. 1998) led us to investigate whether $\mathrm{CGE}$ and $\mathrm{CM}$ require a different number of $\left[\mathrm{Ca}^{2+}\right]_{\mathrm{i}}$ oscillations. 

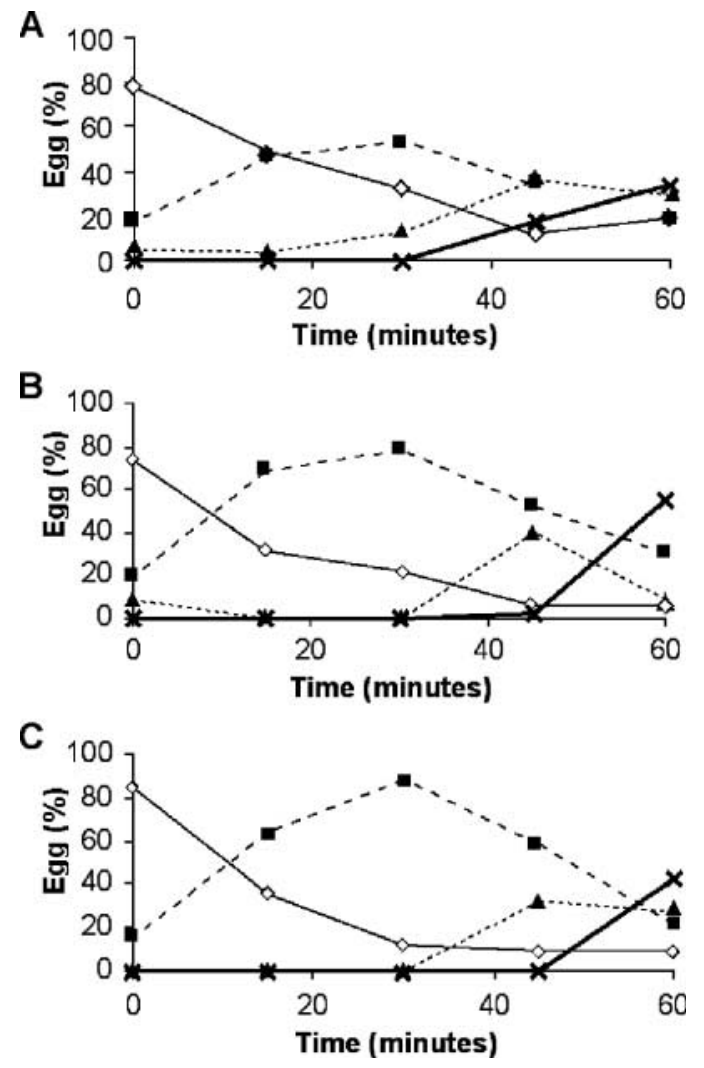

Figure 2 Completion of meiosis induced by 2, 4 or $6 \mathrm{mM} \mathrm{SrCl}_{2}$. Eggs were collected $14 \mathrm{~h}$ after hCG administration and activated by exposure to 2, 4 or $6 \mathrm{mM} \mathrm{SrCl}_{2}$. MIl eggs were exposed for $8 \mathrm{~min}$ to $2 \mathrm{mM}$ (A), $4 \mathrm{mM}$ (B) or $6 \mathrm{mM}$ (C) $\mathrm{SrCl}_{2}$ in $\mathrm{TH}-/-$ medium, washed and cultured in $\mathrm{TH}$ medium for additional time periods to complete a total of 15, 30, 45 or 60 min in culture. Each graph represents 9 experiments, performed on different days. At least 25 eggs were examined at each time point on each experimental day. Time (min) indicates total time in culture. Eggs (\%) indicates the percent of eggs at MII $(\diamond)$, anaphase $(\mathbf{\square})$, telophase $(\boldsymbol{\Lambda})$ and PBII $(X)$.

$\mathrm{SrCl}_{2}(2 \mathrm{mM})$ caused $\left[\mathrm{Ca}^{2+}\right]_{\mathrm{i}}$ oscillations with a $6.6 \mathrm{~min}$ peak-to-peak interval (Table 1). We exposed the eggs to $2 \mathrm{mM} \mathrm{SrCl}_{2}$ for 8, 15 or $60 \mathrm{~min}$, which was expected to induce 1, 2 or 10 oscillations respectively, and then transferred them into $\mathrm{TH}$ medium to complete a period of $60 \mathrm{~min}$ in culture. The eggs were fixed and labeled for
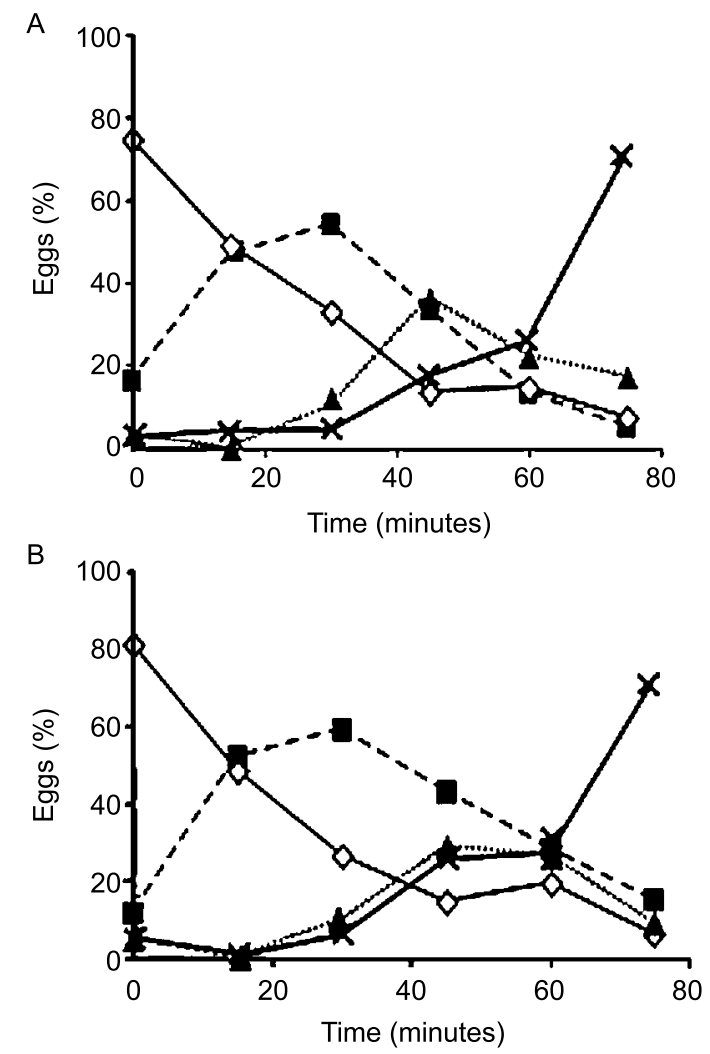

Figure 3 Completion of meiosis induced by either ionomycin or $\mathrm{SrCl}_{2}$. Eggs were collected $14 \mathrm{~h}$ after hCG administration and activated by exposure to $2 \mathrm{mM} \mathrm{SrCl}_{2}$ for $8 \mathrm{~min}$ (A) or to $2 \mu \mathrm{M}$ ionomycin for $5 \mathrm{~min}(\mathrm{~B})$ in $\mathrm{TH}-1-$ medium, washed and cultured for additional time periods in TH medium to complete 15, 30, 45, 60 or $75 \mathrm{~min}$ in culture. Each graph represents 5 experiments performed on different days. At least 25 eggs were examined at each time point on each experimental day. Time (minutes) indicates total time in culture. Eggs $(\%)$ indicates the percent of eggs at MII $(\diamond)$, anaphase $(\boldsymbol{\square})$, telophase $(\mathbf{\Lambda})$ and PBII $(\mathrm{X})$.

CGE and for DNA. Longer exposure to $\mathrm{SrCl}_{2}$ (15 vs $8 \mathrm{~min}$ ) correlated with a higher rate of PBII extrusion $(44 \%$ vs $34 \%$ respectively; $P<0.01$ ). However, eggs exposed to $\mathrm{SrCl}_{2}$ for $60 \mathrm{~min}$ proceeded from MII to anaphase (34\%) and telophase $(36 \%)$, but only $18 \%$ extruded PBII $(P<0.01$; Fig. 5).

Table 2 Intensity of CGE after activation by $\mathrm{SrCl}_{2}$, ionomycin or fertilization. Data were obtained from three experiments. CGE values are means \pm S.E.M

\begin{tabular}{lccc}
\hline Treatment & Estimated number of $\mathbf{C a}^{2+}$ oscillations & Eggs $(n)$ & CGE relative intensity \\
\hline $2 \mathrm{mM} \mathrm{SrCl}_{2}$ for $8 \mathrm{~min}$ & 1 & 40 & $1.89 \pm 0.19 *$ \\
$2 \mathrm{mM} \mathrm{SrCl}_{2}$ for $15 \mathrm{~min}$ & 2 & 40 & $2.11 \pm 0.18 *$ \\
$2 \mathrm{mM} \mathrm{SrCl}_{2}$ for $60 \mathrm{~min}$ & 10 & 30 & $2.07 \pm 0.17 *$ \\
lonomycin & 1 & 40 & $1.00 \pm 0.00$ \\
Fertilization in vivo & & 30 & $1.81 \pm 0.08 *$ \\
\hline
\end{tabular}

The values obtained for ionomycin-activated eggs were arbitraily set at 1.0.

$* P<0.01$ compared with ionomycin-activated eggs. 


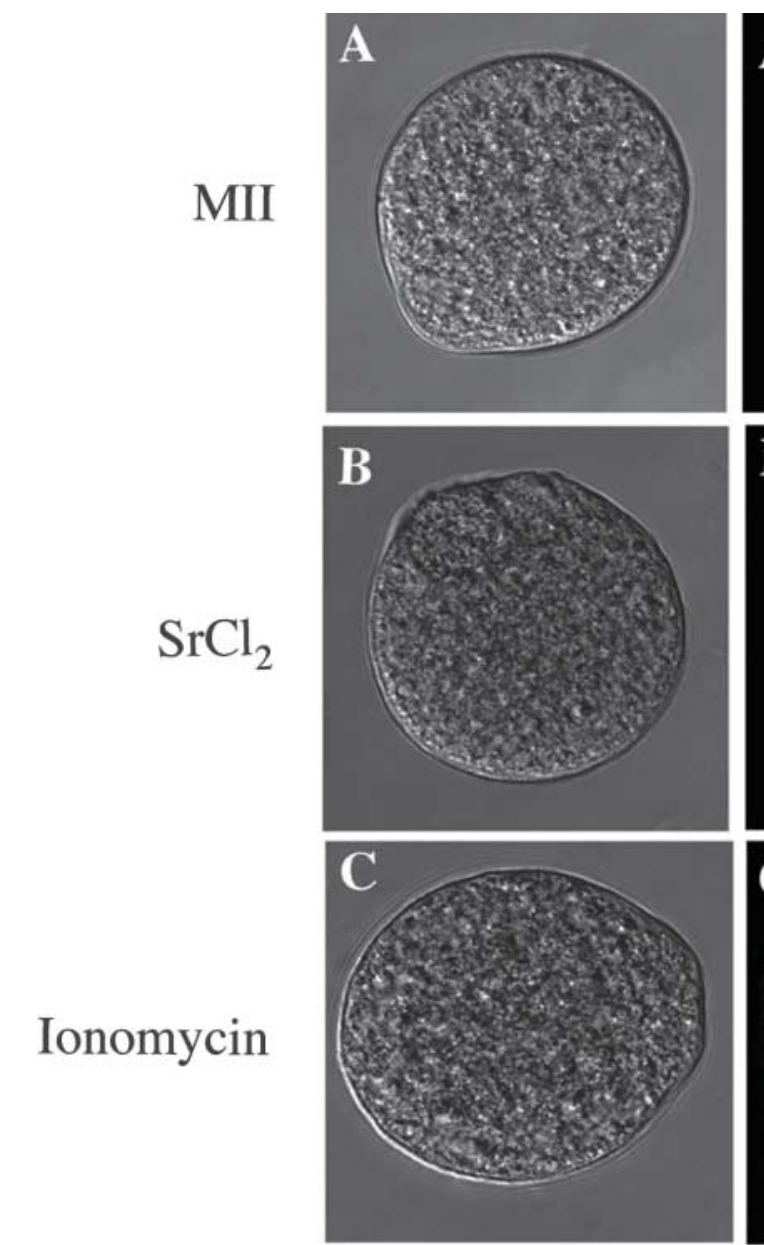

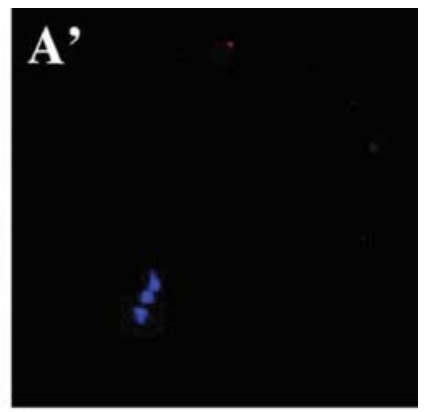
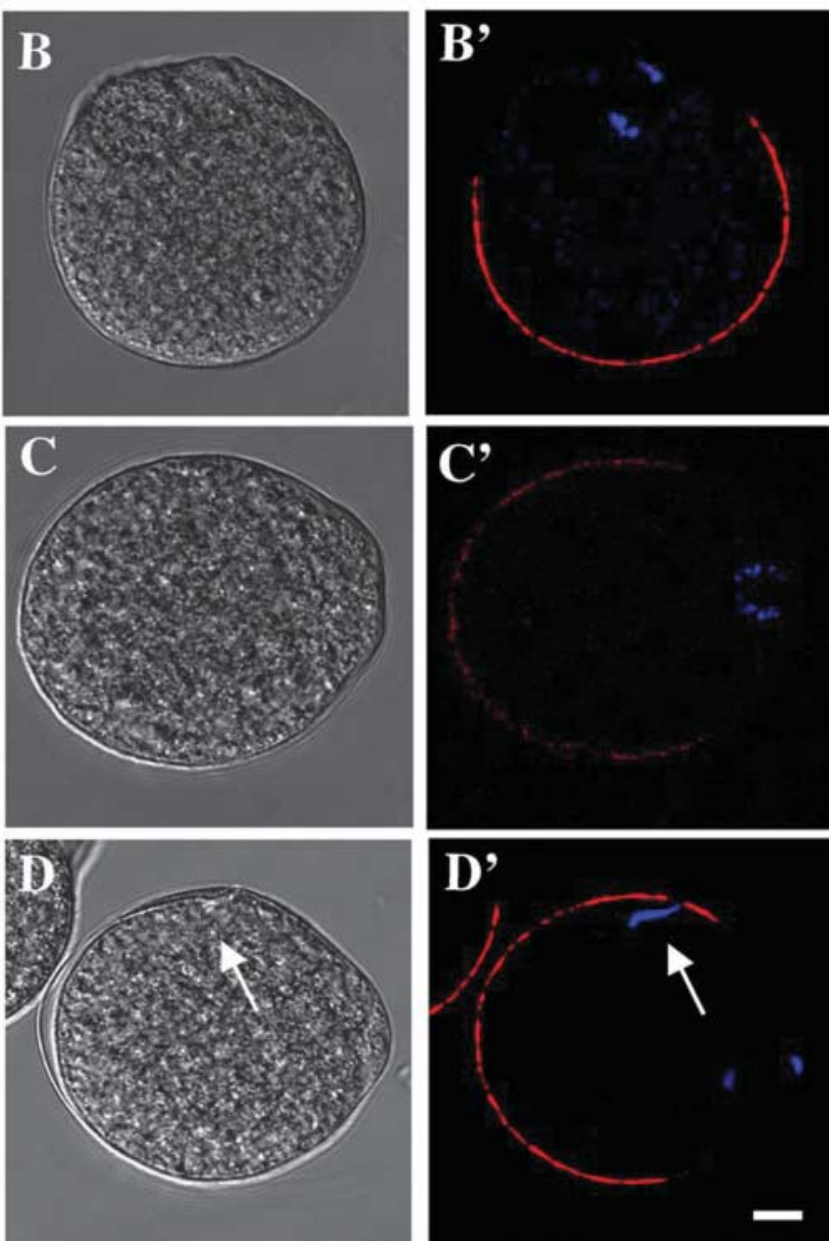

Figure 4 CGE in eggs induced by $\mathrm{SrCl}_{2}$, ionomycin or sperm. A-D, light microscope; $A^{\prime}-D^{\prime}$, fluorescence microscope. Representative confocal micrographs of eggs, colabeled for CGE (red) and DNA (blue) are shown. MII; metaphase II eggs were cultured for $8 \mathrm{~min}$ in $\mathrm{TH}-/-$ medium devoid of activators followed by 37 min in TH medium (control; $A, A^{\prime}$ ). $\mathrm{SrCl}_{2}$ : eggs were cultured for $8 \mathrm{~min}$ in $2 \mathrm{mM} \mathrm{SrCl}_{2}$ in $\mathrm{TH}-1-$ medium followed by $37 \mathrm{~min}$ in $\mathrm{TH}$ medium $\left(\mathrm{B}, \mathrm{B}^{\prime}\right)$. lonomycin: eggs were cultured for $5 \mathrm{~min}$ in $2 \mu \mathrm{M}$ ionomycin in $\mathrm{TH}-1-$ medium followed by $40 \mathrm{~min}$ in $\mathrm{TH}$ medium $\left(C, C^{\prime}\right)$. Fertilization: in vivo fertilized egg $\left(\mathrm{D}, \mathrm{D}^{\prime}\right)$, arrow indicates the sperm head. Quantification of CGE intensity is presented in Table 2. Scale bar $=10 \mu \mathrm{m}$.
CGE is a rapid process, occurring immediately after sperm-egg interaction. To study whether repetitive oscillations enhance the intensity of CGE induced by the first $\left[\mathrm{Ca}^{2+}\right]_{i}$ transient, we monitored the intensity of CGE after exposure to $\mathrm{SrCl}_{2}$ for 8,15 or 60 min or after fertilization in vivo. A single $\left[\mathrm{Ca}^{2+}\right]_{\mathrm{i}}$ transient caused CGE of the same intensity regardless of the stimulus $-\mathrm{SrCl}_{2}$ or sperm. Additional oscillations did not enhance the intensity of CGE (Table 2).

\section{Discussion}

$\mathrm{SrCl}_{2}$ is a commonly employed agent for induction of parthenogenetic activation of mouse eggs. Some researchers reported that $\mathrm{SrCl}_{2}$ triggers a series of $\left[\mathrm{Ca}^{2+}\right]_{\mathrm{i}}$ oscillations in mature MII mouse (Kline \& Kline 1992, Bos-Mikich et al. 1993), pig (Okada et al. 2003) and hamster (Tateno \& Kamiguchi 1997) eggs and is able to cause egg activation. In a recent study, the efficiency of $2 \mathrm{mM} \mathrm{SrCl}_{2}$ for parthenogenetic development of rat eggs was tested, but no details were reported regarding its ability to cause $\left[\mathrm{Ca}^{2+}\right]_{i}$ oscillations, CGE or PBII extrusion (Krivokharchenko et al. 2003). The present study examines the effect of $\mathrm{SrCl}_{2}$ on the early temporal correlation among these three parameters of egg activation.

$\mathrm{SrCl}_{2}$, as well as many other parthenogenetic activators ( Ins $_{3}$, sperm factor, thimerosal, adenophostin A) induces repetitive and regular $\left[\mathrm{Ca}^{2+}\right]_{i}$ oscillations and mimics 


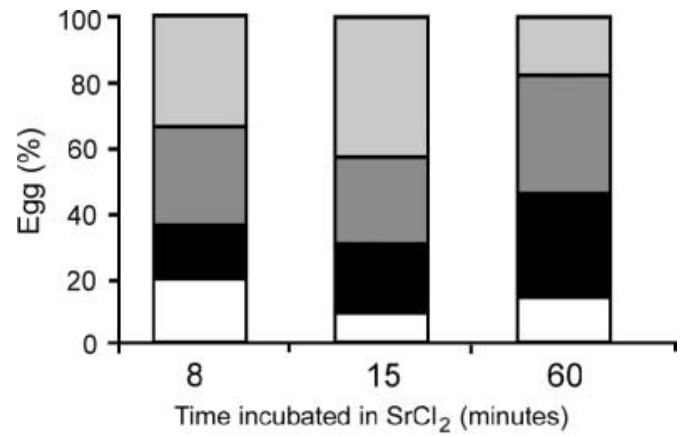

Figure 5 The effect on the progression of $\mathrm{CM}$ incubation in $\mathrm{SrCl}_{2}$. Eggs were cultured in the presence of $2 \mathrm{mM} \mathrm{SrCl}_{2}$ in $\mathrm{TH}-/-$ medium for 8,15 or $60 \mathrm{~min}$ and were then transferred to TH medium to complete a period of $60 \mathrm{~min}$ in culture. Each column represents at least 3 experiments performed on different days. At least 25 eggs were examined at each time point at each experimental day $(P<0.01)$. Time (minutes) indicates the duration of exposure to $\mathrm{SrCl}_{2}$. Eggs (\%) indicates the percent of eggs at MII (white section), anaphase (black section), telophase (dark gray section), and PBII (light gray section) after 60 min culture period.

sperm-induced calcium dynamics. Despite the superficial similarity of the overall phenomena, there are marked differences in the pattern of $\left[\mathrm{Ca}^{2+}\right]_{i}$ changes among the different parthenogenetic stimuli (e.g. Jellerette et al. 2000). Thus, for example, in the rat egg $\mathrm{SrCl}_{2}$ induces a greater first calcium transient, followed by oscillations that are lower in amplitude, more prolonged and of lower frequency than those induced by sperm. By comparison, ionomycin induces only a single calcium transient. Nevertheless, all these agents can cause egg activation up to PBII extrusion. Krivokharchenko et al. (2003) recently reported that ethanol or $\mathrm{SrCl}_{2}$ treatments produced similar success rates of rat embryo implantation. In view of these reports and our own data presented here, what is the importance of the orderly pattern of calcium oscillations induced by sperm and mimicked to a varying degree by other parthenogenetic agents? Are they necessary for the efficient block of polyspermy? Do they support better success rates of activation progression and, ultimately, better rates of implantation?

The only definitive experimental evidence, correlating electropermeabilization-induced calcium oscillations in mouse eggs with $50 \%$ CGE (4 transients) or pronuclei formation (8-24 transients), was reported by Ducibella et al. (2002). Varying the duration of $\mathrm{SrCl}_{2}$ exposure, we could control the number of transients $(1,2$ or 10$)$, yet found there was little difference in the intensity of CGE or the progression to PBII extrusion; these parameters were comparable to those induced by sperm. Actually, 1 or 2 transients exhibited a better rate of PBII extrusion than 10 oscillations, possibly reflecting the toxic effects of prolonged exposure to $\mathrm{SrCl}_{2}$. The differences between the results of Ducibella et al. (2002) and those reported here may be attributed to differences between methods causing a different pattern of $\left[\mathrm{Ca}^{2+}\right]_{i}$ oscillations or differences in species studied.
Although both $2 \mu \mathrm{M}$ ionomycin and 8-min exposure to $2 \mathrm{mM} \mathrm{SrCl} l_{2}$ cause a single $\left[\mathrm{Ca}^{2+}\right]_{i}$ transient, the ionomycin-induced transient is of much lower amplitude. Interestingly, ionomycin evokes a much lower CGE response (see Table 2), but a similar degree of PBII extrusion (Fig. 2). This could be interpreted in terms of two independent processes being initiated by the first $\left[\mathrm{Ca}^{2+}\right]_{\mathrm{i}}$ transient: CGE and CM. The hypothesis that an increase in $\left[\mathrm{Ca}^{2+}\right]_{i}$ is required for CGE is well established (Kline \& Kline et al. 1992, Raz et al. 1998). It is possible that the high transient resulting from $\mathrm{SrCl}_{2}$ exposure, but not from ionomycin, activates $\mathrm{Ca}^{2+}$-dependent proteins such as $\mathrm{Ca}^{2+}$-dependent protein kinase $\mathrm{C}$, which, in turn, affect the degree of CGE (Bos-Mikich et al. 1995, Jellerette et al. 2000). It should be noted that Raz et al. (1998), using ionomycin and BAPTA-AM (to buffer cytosolic $\left[\mathrm{Ca}^{2+}\right]_{\mathrm{i}}$ ), reported that CGE was more sensitive than PBII extrusion to $\left[\mathrm{Ca}^{2+}\right]_{i}$ concentrations. Their experiments, however, were performed in $\mathrm{Ca}^{2+}$-containing medium and the influx of extracellular calcium through the ionophore could account for these differences.

In conclusion, the current study demonstrated that $\mathrm{SrCl}_{2}$ can be used as an easily controlled parthenogenetic agent, which mimics fairly faithfully the early events of egg activation $\left(\left[\mathrm{Ca}^{2+}\right]_{i}\right.$ increase, CM and CGE). Our results, as well as those reported by others, suggest that a single large calcium transient is sufficient for the orderly progression of the egg through these early events. The role of the subsequent transients in the sperm-activated egg is less clear and merits further study.

\section{Acknowledgements}

We gratefully thank Dr Leonid Mittelman for his excellent technical assistance at the confocal microscope.

This work is in partial fulfillment of the requirements for the $\mathrm{PhD}$ degree of R Tomashov-Matar at the Sackler Faculty of Medicine, Tel-Aviv University. The authors declare that there is no conflict of interest that would prejudice the impartiality of this scientific work.

\section{References}

Abbott A, Fissore R \& Ducibella T 1999 Incompetence of preovulatory mouse oocytes to undergo cortical granule exocytosis following induced calcium oscillations. Developmental Biology $20738-48$.

Ben-Yosef D, Oron Y \& Shalgi R 1993 Prolonged, repetitive calcium transients in rat oocytes fertilized in vitro and in vivo. FEBS Letters 331 239-242.

Ben-Yosef D, Oron Y \& Shalgi R 1996 Intracellular pH of rat eggs is not affected by fertilization and the resulting calcium oscillations. Biology of Reproduction 55 461-468.

Bos-Mikich AB, Swann K \& Whittingham DG 1993 Sr$^{2+}$-induced parthenogenetic activation of mouse oocytes is enhanced by cycloheximide. Journal of Reproduction and Fertility Abstract Series 12-18.

Bos-Mikich AB, Swann K \& Whittingham DG 1995 Calcium oscillations and protein synthesis inhibition synergistically activate mouse oocytes. Molecular Reproduction and Development 41 $84-90$. 
Brind S, Swann K \& Carroll J 2000 Inositol 1,4,5-trisphosphate receptors are downregulated in mouse oocytes in response to sperm or adenophostin A but not to increases in intracellular $\mathrm{Ca}^{2+}$ or egg activation. Developmental Biology 223 251-265.

Carroll J 2001 The initiation and regulation of $\mathrm{Ca}^{+2}$ signaling at fertilization in the mammals. Seminars in Cell and Developmental Biology 12 37-43.

Ducibella T, Huneau D, Angelichio E, Xu Z, Schultz R, Kopf G, Fissore R, Madoux S \& Ozil JP 2002 Egg to embryo transition is driven by differential responses to $\mathrm{Ca}^{2+}$ oscillation number. Developmental Biology 250 280-291.

Dupont G, McGuiness $O$, Johnson MH, Berridge MJ \& Borgese $F$ 1996 Phospholipase $\mathrm{C}$ in mouse oocytes: characterization of isoforms and their possible involvement in sperm-induced $\mathrm{Ca}^{+2}$ spiking. Biochemistry Journal 316 583-591.

Eliyahu E \& Shalgi R 2002 A role for protein kinase C during rat egg activation. Biology of Reproduction 67 189-195.

Fissore RA, Dobrinsky JR, Balise JJ, Duby RT \& Robl JM 1992 Patterns of intracellular $\mathrm{Ca}^{2+}$ concentration in fertilized bovine oocytes. Biology of Reproduction 47 960-969.

Gordo AC, Wu H, He CL \& Fissore RA 2000 Injection of sperm cytosolic factor into mouse metaphase II oocyte induces different development fats according to the frequency of $\left[\mathrm{Ca}^{2+}\right]_{1}$ oscillations and oocyte age. Biology of Reproduction 62 1370-1379.

Hyslop LA, Nixon VL, Levasseur M, Chapmann F, Chiba K, McDougall A, Venables JP, Elliott DJ \& Jones KT $2004 \mathrm{Ca}^{2+}$-promoted cyclin B1 degradation in mouse oocytes requires the establishment of a metaphase arrest. Developmental Biology 269 206-219.

Jellerette T, He CL, Wu H, Parys JB \& Fissore RA 2000 Down-regulation of the inositol 1,4,5-trisphosphate receptor in mouse eggs following fertilization or parthenogenetic activation. Developmental Biology 223 238-250.

Jones KT 2004 Turning it on and off: M-phase promoting factor during meiotic maturation and fertilization. Molecular Human Reproduction $101-5$.

Kishikawa H, Wakayama T \& Yanagimachi R 1999 Comparison of oocyte activating agents for mouse cloning. Cloning $\mathbf{1} 153-159$.

Kline D \& Kline D 1992 Repetitive calcium transient and the role of calcium in exocytosis and cell cycle activation in the mouse egg. Developmental Biology 149 80-89.

Krivokharchenko A, Popova E, Zaitseva I, Vil'ianovich L, Ganten D \& Bader M 2003 Development of parthenogenetic rat embryos. Biology of Reproduction 68 829-836.

Marshall IC \& Taylor CW 1994 Two calcium-binding sites mediated the interconversion of liver inositol 1,4,5-trisphosphate receptors between three conformational states. Biochemistry Journal 301 591-598.

Mehlmann LM, Carpenter G, Rhee SG \& Jaffe LA 1998 SH2 domainmediated activation of phospholipase $\mathrm{C}$ is not required to initiate $\mathrm{Ca}^{+2}$ release at fertilization of mouse eggs. Developmental Biology $203221-232$.
Nixon VL, McDougall A \& Jones KT $2000 \mathrm{Ca}^{+2}$ oscillations and the cell cycle at fertilization of mammalian and ascidian eggs. Biology of the Cell 92 187-196.

Okada K, Miyano T \& Miyake M 2003 Activation of pig oocytes by intracytoplasmic injection of strontium and barium. Zygote $\mathbf{1 1}$ 159-165.

O'Neill GT, Rolfe LR \& Kaufman MH 1991 Developmental potential and chromosome constitution of $\mathrm{SrCl}_{2}$-induced mouse parthenogenones. Molecular Reproduction and Development 30 214-219.

Otaegui PJ, O'Neill GT \& Wilmut I 1999 Parthenogenetic activation of mouse oocyte by exposure to $\mathrm{SrCl}_{2}$ as a source of cytoblasts for nuclear transfer. Cloning 111-117.

Ozil JP \& Huneau D 2001 Activation of rabbit oocyte: the impact of the $\mathrm{Ca}^{2+}$ signal regime on development. Development 128 917-928.

Parrington J, Brind S, De Smedt H, Gangeswaran R, Lai FA, Wojcikiewicz R \& Carroll J 1998 Expression of inositol 1,4,5-trisphosphate receptors in mouse oocytes and early embryos: the type I isoform is upregulated in oocytes and down-regulated after fertilization. Developmental Biology 203 451-461.

Patel S, Joseph SK \& Thomas AP 1999 Molecular properties of inositol 1,4,5-trisphosphate receptors. Cell Calcium 25 247-264.

Raz T \& Shalgi R 1998 Early events in mammalian egg activation. Human Reproduction 13 133-145.

Raz T, Ben-Yosef D \& Shalgi R 1998 Segregation of the pathways leading to cortical reaction and cell cycle activation in the rat egg. Biology of Reproduction 58 94-102.

Shalgi R \& Phillips DM 1988 Motility of rat spermatozoa at the site of fertilization. Biology of Reproduction 39 1207-1213.

Talmor A, Kinsey WH \& Shalgi R 1998 Expression and immunolocalization of p59 c-Fyn tyrosine kinase in rat egg. Developmental Biology 194 38-46.

Tateno H \& Kamiguchi Y 1997 Parthenogenetic activation of Chinese hamster oocytes by chemical stimuli and its cytogenetic evaluation. Molecular Reproduction and Development 47 72-78.

Taylor CW 1998 Inositol trisphosphate receptors: $\mathrm{Ca}^{2+}$-modulated intracellular $\mathrm{Ca}^{2+}$ channels. Biochimica et Biophysica Acta 1436 19-33.

Wakayama T, Perry AC, Zuccotti M, Johnson KR \& Yanagimachi R 1998 Full-term development of mice from enucleated oocytes injected with cumulus cell nuclei. Nature 394 369-374.

Whitaker M \& Larman MG 2001 Calcium and mitosis. Cell and Developmental Biology 12 53-58.

Received 29 March 2005

First decision 23 May 2005

Revised manuscript received 2 June 2005

Accepted 21 June 2005 